2014

\title{
The Influences of Strategic Management on Antitrust Discourse
}

Hillary Greene

University of Connecticut School of Law

Dennis A. Yao

Harvard University

Follow this and additional works at: https://opencommons.uconn.edu/law_papers

Part of the Antitrust and Trade Regulation Commons

\section{Recommended Citation}

Greene, Hillary and Yao, Dennis A., "The Influences of Strategic Management on Antitrust Discourse" (2014). Faculty Articles and Papers. 478.

https://opencommons.uconn.edu/law_papers/478 


\title{
$\prod_{\text {he influences of strategic }}$ management on antitrust discourse
}

\author{
By Hillary GREENE* \& DeNNIS A. YAO**
}

This article examines how antitrust law and policy can benefit from ideas developed in the academic strategy field. Because accurate assessment and prediction of the effects of firm conduct depend in part on understanding individual firm capabilities, knowledge from the strategy field and other business fields complements the contributions from industrial organization economics (IO). These business fields also offer theoretical and empirical challenges to the IO paradigm, which dominates antitrust analysis. The article begins with a comparison between strategy and IO and then illustrates how the strategy field can contribute to antitrust merger analysis. The article then assesses the influence of the strategy field on antitrust law and scholarship based on a citation analysis, which reveals little evidence of influence. It concludes with an examination of the likely impediments to the diffusion of strategy field ideas into antitrust.

KEY WORDS: antitrust, mergers, industrial organization, business strategy, diffusion of ideas, merger guidelines

* Professor of Law, University of Connecticut School of Law, Senior Visiting Scholar, UC Berkeley School of Law and Visiting Scholar, UC Berkeley College of Engineering (Fung Institute).

** Lawrence E. Fouraker Professor of Business Administration, Harvard Business School and Visiting Scholar, Haas School, UC Berkeley and UC Berkeley College of Engineering (Fung Institute). I served as a commissioner of the Federal Trade Commission from 1991-94.

AUTHORS' NOTE: A preliminary version of this article was presented at the American Antitrust Institute's symposium "Antitrust as an Interdisciplinary Field: Insights from Business Strategy and Research" (Washington, DC 2013). We thank Greg Gundlach and an anonymous referee for helpful comments, Lydia Kim for research assistance, and Erin McDonagh for editorial assistance. The views expressed here are solely ours.

(C) 2014 by Federal Legal Publications, Inc. 


\section{INTRODUCTION}

The purpose of antitrust law is to "protect economic freedom and opportunity by promoting free and fair competition in the marketplace." ${ }^{1}$ Determining whether a firm has engaged in anticompetitive conduct depends on whether the activity impairs, or would impair, the functioning of the marketplace resulting in harm to welfare. Over time, antitrust law has relied increasingly on teachings from industrial organization economics (IO) to provide theory regarding how markets work and to provide tools for either measuring or predicting the competitive effects at issue.

While antitrust has integrated IO into its policy and legal determinations, we argue that antitrust has not sufficiently relied upon comparable teachings from the academic business fields despite their relevance to the actions being scrutinized. ${ }^{2}$ Business fields such as marketing, operations, organizational behavior, and strategy examine diverse subjects including the decision making, performance, and organizational processes of firms. All of these fields contribute to subjects that are critical to making antitrust determinations. In practice, however, those contributions have arguably received less attention from the antitrust community than is deserved, in part because the fields do not prioritize research that seeks to further antitrust goals.

While many contributions from strategy (as well as from other business fields) complement those of IO, sometimes its contributions

See U.S. Dep't of Justice, Antitrust Division, Mission Statement, available at www.justice.gov/atr/about/mission.

2 Dennis A. Yao, Commissioner, Federal Trade Comm'n, Prepared Remarks Before the Illinois State Bar Association and Chicago Bar Ass'n (Dec. 2, 1992) (on file with author); Michael E. Porter, Competition and Antitrust: Towards a Productivity-Based Approach to Evaluating Mergers and Joint Ventures, 46 AnTITRUST Bull. 919 (2001); Spencer Weber Waller, The Language of Law and the Language of Business, 52 CASE W. RES. L. REV. 283, 283-84 (2001); Norman W. Hawker The Public Policy of Antitrust and Strategy: An Overview, 21 J. PuB. POL'Y \& MARKETING 257 (2002); Albert A. Foer, The Third Leg of the Antitrust Stool: What the Business Schools Have to Offer to Antitrust, 47 N.Y.L. SCH. L. REv. 21, 49 (2003); Thomas B. Leary, The Dialogue Between Students of Business and Students of Antitrust: A Keynote Address, 47 N.Y.L. SCH. L. Rev. 1, 5 (2003); Felix Oberholzer-Gee \& Dennis A. Yao, Antitrust-What Role for Strategic Management Expertise?, 90 B.U. L. REV. 1457 (2010). 
offer theoretical and empirical challenges to IO and, by extension, to IO-based antitrust analysis. The divergence between IO and the strategy field reflects, in part, the latter's heavy reliance on disciplines other than economics. We believe that the business fields provide valuable frameworks and insights that would assist in improving antitrust theory, making key factual determinations, including those undergirding competitive effects analysis, and predicting the effects of various proposed antitrust remedies.

This article examines how antitrust law and policy can benefit from ideas developed in the academic strategy field, which has as its focus how firms achieve and sustain competitive advantage over their rivals. While surveying the entire range of business fields and their respective capacities to contribute to antitrust analysis is beyond the scope of this article, many of the arguments framed with regard to strategy would apply to other business fields as well. ${ }^{3}$

Part II begins with a brief description of strategy scholarship and how it compares to IO scholarship. In comparing economics, and particularly IO, to the strategy field, we use mainstream IO as our point of reference and focus on the first-order differences that characterize each field. We recognize that research in $\mathrm{IO}$, and for that matter in strategy, is heterogeneous and that exceptions to our characterization are inevitable. Part III illustrates how strategy insights can prove valuable in the context of antitrust merger review. Part IV offers some preliminary evidence concerning the direct influence of strategy on antitrust law and scholarship. The statistics show that the influence of strategy is quite limited, though some weak evidence suggests that strategy's influence may be increasing. Part $\mathrm{V}$ assesses how ideas from the strategy field can influence antitrust law and suggests which types of ideas and analyses are more likely to be adopted. Part VI concludes.

\section{THE STRATEGY FIELD AND ITS RELATIONSHIP TO ANTITRUST}

Part II describes the focus of the strategy field and summarizes its relationship to IO with a particular emphasis upon key differences

3 See Gregory T. Gundlach, Joan M. Phillips \& Debra M. Desrochers, Antitrust and Marketing: A Primer and Call to Research, 21 J. PUB. POL'Y \& MARKETING 232 (2002). 
between them. ${ }^{4}$ It then delineates, in general terms, the value to antitrust from greater engagement with the strategy field. While strategy and IO represent two distinct fields, their relationship is complex because they effectively overlap on various points; there are diverse perspectives within each field; and the contours of each field, their relationship to each other and to antitrust continue to change over time.

\section{A. Understanding strategy's relationship to industrial organization economics}

The strategy field examines how firms achieve and sustain competitive advantage over their rivals. Its primary focus is individual firm performance - a firm's ability to create and to capture value and, ultimately, to sustain supranormal profits. Most strategy research operates at the firm level and adopts as its baseline assumption that firms in the same industry typically have important differences in terms of their capabilities and frequently their strategies. ${ }^{5}$ These differences, in turn, explain the distribution of profits among firms within an industry. In contrast, IO research focuses primarily on market structure and market performance and operates largely at the industry level of analysis. ${ }^{6}$ Because the focus is at the market-industry level, specific differences among firms are not emphasized.

Importantly, strategy is an inherently multidisciplinary field. It draws heavily from the disciplines of economics and sociology and, to a lesser extent, from psychology, as well as from applied business fields such as organizational behavior, marketing, and technology management. Owing to this reliance on such eclectic disciplines and fields, strategy scholarship variously reflects both the rational actor,

4 See Dennis A. Yao, Business Strategy from Alternative Perspectives, 12 ANTITRUST 16 (1998).

A "strategy" is defined in the literature as a plan that specifies the product and geographic space in which a firm competes and how the firm will achieve competitive advantage in that space. See, e.g., DAVID J. Collis \&

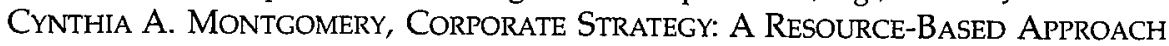
(2d ed. 2005).

6 We use the terms market level analysis (used more frequently in IO and antitrust) interchangeably with industry level analysis (used more frequently in the strategy field and which could include multiple markets). 
optimizing approach of IO as well as the behavioral perspectives of sociology and psychology. Several different schools of thought characterize the strategy field. This heterogeneity reflects, in part, the strategy schools' differing emphases regarding economic and behavioral factors. Schools with comparatively greater reliance on economics include the positioning and resource-based approaches. The evolutionary school exemplifies a more behaviorally based approach.

The positioning school analyzes firms as bundles of interconnected activities (such as logistics, operations, and marketing) that serve a targeted set of customers through a particular strategy. ${ }^{7} \mathrm{~A}$ firm's current position necessarily reflects tradeoffs just as it would incur costs if it sought to reposition itself to serve other customer segments or serve current customers in a different manner. The costs associated with (re)positioning are highly fact-specific and can range from modest to prohibitive. Firms optimize competitive advantage by honing their individual activities to build positively reinforcing interactions among the activities and to eliminate or modify activities that customers insufficiently value. ${ }^{8}$

The resource-based view of the firm (RBV school) $)^{9}$ focuses on the importance to firm performance of possessing and utilizing scarce resources which, when combined with more commonplace resources,

7 Michael E. Porter, What Is Strategy?, 74 Harv. Bus. Rev. 61 (1996), and Michael E. Porter, Competitive Advantage (1985). The positioning school started as an application of IO to firm performance questions and, as such, many important aspects of this school follow directly from IO principles. For example, Porter's well-known "five forces" analysis adapts value capture dynamics in a manner consistent with economic principles. Michael E. Porter, How Competitive Forces Shape Strategy, 57 Harv. Bus. REv. 137 (1979) [hereinafter Porter, How Competitive Forces].

8 One important variant of the positioning school, value-based business strategy, uses an added-value concept to predict how a consumer's willingness to pay for a product (that is, the product's total value) is divided among the vertical chain participants that produce and deliver the product to consumers. Adam Brandenberger \& Harborne Stuart, Value-Based Business Strategy, 5 J. ECON. \& MGMT. STRATEGY 5 (1996).

9 Birger Wernerfelt, A Resource-Based View of the Firm, 5 STRATEGIC MgmT. J. 171 (1984). See also Collis \& Montgomery, supra note 5, for an excellent summary of the RBV school. 
create a firm's distinctive capabilities. ${ }^{10}$ Resources include tangible assets or intangible assets such as brand loyalty or implicit production know-how. Resources can include production and decision-making knowledge that is embedded in organizational and decision routines as well as formal and informal organizational structure itself. ${ }^{11}$

The more economics-based schools of strategy, of course, share common baseline assumptions with IO. This is particularly true of the positioning school in which the attractiveness of positions is determined with reference to market structure and market competition. The RBV school focuses more directly on the firm itself, but its key resource-based construct is also defined with reference to many market-oriented considerations such as competition and imitation. Both of these schools also assume at least a modest degree of rational decision making. This use of economic logic and analysis makes their respective teachings relatively complementary to those of IO.

Albeit to varying degrees, all strategy schools incorporate behavioral factors into their explanations regarding sustainable firm profits. These factors include myopic decision making and bounded rationality, the (noneconomic) nature of social interactions, various types of individual and group decision biases, as well as various organizational forces. For some schools, however, behavioral considerations figure more prominently. The evolutionary school, for example, stresses the importance of boundedly rational decision making and local search. ${ }^{12}$ According to this school, firms typically make choices

10 Key capabilities are also termed core competencies. C.K. Prahalad \& Gary Hamel, The Core Competence of the Corporation, 68 HARV. BUS. REv. 79 (1990) use a firm's ability to miniaturize components as an example of a core competence. Strategy scholars have also emphasized the central role of dynamic capabilities that allow a firm to change its capability set to better handle a quickly changing environment. See, e.g., DAVID J. TEECE, DYNAMIC Capabilities \& Strategic Management (2009).

11 Bruce Kogut \& Udo Zander, Knowledge of the Firm, Combinative Capabilities, and the Replication of Technology, 3 ORG. SCI. 383, 389 (1992).

12 The evolutionary school of strategy derives from the behavioral theory of the firm (RiCHARD CYERT \& JAMES MARCH, A BEHAVIORAL THEORY OF THE FIRM (1963)), with strong influences from evolutionary theorists in both economics (RICHARD NELSON \& SidNEY WINTER, AN EVOlutionary THEORY OF ECONOMIC 
over a small set of options and exhibit limited foresight. Some firms will even "satisfice." The creation of productive and market knowledge is considered firm-specific and path-dependent which, in turn, implies that knowledge and production capabilities will differ across firms within an industry. Furthermore, the school assumes that a portion of a firm's productive knowledge is understood implicitly and is therefore difficult for firms to imitate or even exchange. ${ }^{33}$

As one moves from the more economics-based schools to the more behaviorally oriented schools, such as the evolutionary school of strategy, the differences with IO increase. Economic mechanisms such as competition and economic incentives coupled with assumptions regarding optimization and foresight are increasingly deemphasized, while behavioral assumptions regarding myopic decision making, organizational dynamics, and social network structures are increasingly emphasized. ${ }^{14}$ Work in the behavioral tradition may directly challenge the predictions of economics and provide alternative answers to questions posed in the IO literature, as well as introduce different questions. ${ }^{15}$

Notwithstanding the foregoing discussion regarding significant variations between various strategy-based schools of thought, the

Change (1982)), and sociology (PHILIP SElzNICK, TVA AND the GRAss RoOTS: A Study of Politics and Organization (1949); GlenN R. Carroll \& Michael T. Hannan, The Demography of CoRporations and Industries (2004)). The school rejects the general neoclassical economics assumption that firms globally maximize. See, for example, Giovanni Gavetti, Daniel Levinthal \& William Ocasio, Neo-Carnegie: The Carnegie School's Past, Present, and Reconstructing for the Future, 18 ORG. SCI. 523 (2007), for a critical review of developments in the behavioral theory of the firm.

13 Gabriel Szulanski, Exploring Internal Stickiness: Impediments to the Transfer of Best Practice Within the Firm, 17 StRategic MGMT. J. 27 (1996).

14 Some strategy research emphasizes entrepreneurship as a key process for value creation. Because of the difficulties associated with discovering and implementing game-changing ideas, such research generally emphasizes behavioral constraints as well. See, e.g., Giovanni Gavetti, Toward a Behavioral Theory of Strategy, 23 ORG. SCI. 267 (2012); W. ChAN KIM \& RENÉ MAUBORGNE, Blue Ocean Strategy: How to Create Uncontested Market Space and MaKe COMPETITION IRRELEVANT (2005).

15 See supra note 12. 
field of strategy writ large can be understood in terms of certain core perspectives that differ from those characterizing the IO field. Toward that end, table 1 provides a brief and stylized comparison of key dimensions along which the IO and strategy perspectives differ. ${ }^{16}$

Table 1

Stylized Comparison of Strategy and IO Economics Perspectives

\begin{tabular}{lll} 
& Strategy & IO Economics \\
Primary level of analysis & Firm & Industry \\
Firm ability to change & Constrained & $\begin{array}{l}\text { Relatively unconstrained } \\
\text { Firm decision making }\end{array}$ \\
$\begin{array}{lll}\text { Boundedly rational } \\
\text { and relatively myopic }\end{array}$ & $\begin{array}{l}\text { Rational and with } \\
\text { foresight }\end{array}$ \\
Firm similarity within & Heterogeneous & Relatively homogenous \\
\hline
\end{tabular}

A key source of differences between the strategy field and IO is that strategy focuses on complex and often system-level differences among firms, whereas $I O$ focuses on market outcomes in which firms differ in limited ways (such as that all firms have access to the same production function, but firm-specific costs reflect units sold, production capacities, or access to intellectual property). Because explaining sustainable profits resulting from strategy also entails understanding the system of interactions that constitute a firm, strategy embraces more complex and less-well-defined problems than IO has traditionally addressed.

In addition to the different level of analysis, IO's more "black box" view of the firm leads IO scholars to view the firms as more similar than different, more malleable, and more characterized by making optimizing decisions. Essentially, behavioral constraints on firm action as well as the path dependence associated with each firm's history, both of which many strategy schools deem critical to understanding firm performance, are relatively suppressed in the conventional IO

${ }^{16}$ See also Richard P. Rumelt, Dan Schendel \& David J. Teece, Strategic Management and Economics, 12 STRATEGIC MGMT. J. 5-6 (1991); Felix Oberholzer-Gee \& Dennis A. Yao, Market Imperfections and Sustainable Competitive Advantage, in OXFORD HANDBOOK IN MANAGERIAL ECONOMICS 262-77 (Christopher R. Thomas \& William F. Shughart II eds., 2013). 
view of the firm. IO economists recognize, of course, that firms can and do differ, but they believe that questions regarding market structure as well as firm performance can be answered satisfactorily using simplifying assumptions regarding firm heterogeneity. ${ }^{17}$ Moreover, $\mathrm{IO}$ scholars also argue that firms in more mature markets make relatively rational and optimizing decisions, because firms that do not act this way would be driven out of the market by those that do. ${ }^{18}$

\section{B. Understanding the significance of the strategy and IO relationship for antitrust}

Because $I O$ is already established as the primary social science foundation for antitrust law, strategy's contributions to antitrust are usefully understood in terms of their additions or modifications to the existing IO foundation. Section II.A provided background for this assessment by examining the general differences between the strategy and IO fields as well as some specific differences among the strategy schools. As discussed, the strategy field can provide the antitrust community with insights regarding-the mechanisms through which firms make decisions, create competitive advantage, and achieve superior performance. While such insights do not directly illuminate market performance, they are often critical to predicting which forces will affect market performance and for explaining or evaluating firms' past actions.

Strategy's additional contributions to antitrust, relative to those of $\mathrm{IO}$, can be usefully understood with reference to the degree of com-

17 Strategy scholars argue that the documented, wide variations between firms' performances within an industry underscores the inadequacy of using industry characteristics as the primary bases for understanding firm conduct and performance. See Richard P. Rumelt, How Much Does Industry Matter? 12 Strategic MGmT. J. 167 (1991), and Anita McGahan \& Michael E. Porter, How Much Does Industry Matter, Really?, 18 STRATEGIC MGMT. J. 15 (1997), for a debate regarding how much of the variability of profits across firms in the economy is attributable to differences among firm characteristics versus differences among industry characteristics.

18 There is some irony in this argument, at least with regard to antitrust, as the subjects of interest will often not face the full force of competition in their markets and, hence, may not need to optimize to survive. 
patibility between the two fields. Strategy insights that reinforce the IO paradigm are at one pole, while insights that directly challenge the IO paradigm occupy the other pole. Between those two extremes are more nuanced relationships between the fields. For example, strategy teachings may differ from IO and yet be largely complementary. This would occur if strategy incorporates factors that IO does not recognize but whose treatment does not preclude factors that IO favors.

The contributions of economics-based schools of strategy, unsurprisingly, tend to be most compatible with IO. In fact, many key strategy concepts such as Porter's five forces framework developed as applications of IO to strategy questions..$^{19}$ Other ideas, such as viewing the firm as a value chain composed of various interacting activities, provide a distinct perspective on firm choice and performance that still remains largely consistent with IO principles. ${ }^{20}$ The value of these concepts is that they provide antitrust with frameworks, distinct from those IO provides, to understand firm choices that reflect, for example, the complexities of production activity systems or formal and informal organizational relationships. Even when strategy frameworks are relatively openended, and therefore less useful for prediction of firm decisions or market outcomes, the frameworks still contribute useful organizing principles for evaluating business documents and testimony. ${ }^{21}$

The theories and evidence associated with the more behaviorally oriented strategy schools tend to be less compatible with the IO paradigm than those of the more economics-oriented schools. The behaviorally-oriented approaches reflect the additional perspectives of sociology, psychology, and sometimes political science. Such analyses often directly question and critique key IO assumptions. In turn, these strategy analyses have been criticized when they do not offer viable alternatives for policy. It is, for example, much easier to establish that firm decision making in practice substantially diverges from the

19 Porter, How Competitive Forces, supra note 7.

20 Porter, Competitive AdVANTAGE, supra note 7.

${ }_{21}$ Most frameworks in both strategy and IO assume that the firm is guided by a coherent strategy. But see Henry Mintzberg \& James A. Waters, Of Strategies, Deliberate and Emergent, 6 STRATEGIC MGMT. J. 257 (1985) (observing that many firms lack a deliberate strategy). 
global optimization assumed in many economic theories, than it is to provide a defensible alternative decision-making model. In the short run, such failings may slow the diffusion of knowledge from the behaviorally based strategy schools to antitrust. However, the critiques and empirical observations these perspectives introduce offer the potential for improved antitrust discourse and may provide an impetus to reject or otherwise limit the application of weaker antitrust ideas with limited or disputed empirical bases. ${ }^{22}$

In the longer term, the gap between the contributions to antitrust law produced by IO and strategy fields collectively and those produced by $\mathrm{IO}$ alone depends on what research questions are posed and whether the answers to those questions differ. It was noted previously that IO and strategy generally address different questions. But in this specific setting, IO's attention to antitrust problems may have steered some IO researchers toward questions that are more firm-specific and, therefore, more strategy-like. ${ }^{23}$ Historically, at least, even when the questions were the same, the answers sometimes differed owing to the two fields' differing perspectives. ${ }^{24}$ This is particularly true with regard to strategy's more behavioral contributions.

Other factors that render distinctive the contributions of strategy and IO to antitrust involve the two fields' differing restrictions and

22 Well-accepted theories influence antitrust decisions even when the evidence is lacking to support their specific application to the firms and market in question. Their deployment under such circumstances reflects the abiding assumption that the conditions under which those theories operate are present, if not observable. Strategy scholarship with its attention to firm-specific differences is valuable in helping to understand the boundary conditions of various economic (and strategy) theories.

${ }^{23}$ In the extreme, this view would suggest that in an effort to address all relevant issues posed by antitrust, IO would engage relevant questions that would normally be in the strategy domain. Not withstanding the difficulties IO would have addressing behaviorally oriented forces, in our opinion such an extreme conclusion reflects an unduly optimistic view regarding how a field with an established paradigm develops knowledge.

24 It is important to remember that the IO and strategy fields are not fully distinct as many strategy field researchers are trained as IO economists and, as has been discussed, the origins of some of the schools of strategy can be traced to IO. 
quality standards regarding theory building and empirical research. The development of theories regarding system-level organizational phenomena, for example, is severely hampered by analytical tractability concerns. Strategy's greater emphasis on answering questions regarding matters of design and implementation leads the field to adopt methods that economics relatively disfavors, such as computer simulation models involving somewhat myopic firms, and to be more permissive regarding analytical examples relative to more general theoretical analyses. Additionally, strategy has been arguably more accommodating to empirical studies that suggest important patterns and relationships for which a well-articulated theory may still be lacking.

Given its focus on particular firm performance as well as its desire to capture complex organizational phenomena, strategy scholarship rewards organizational case studies involving extended observation and interviews. ${ }^{25}$ This approach is relatively disfavored by IO and, moreover, the vast majority of economists lack the requisite training to engage in such research. ${ }^{26}$ The strategy field's relative openness regarding methods means that strategy scholars undertake analyses that their economics colleagues tend to discount or even ignore. Hence, to the extent that the antitrust community's reliance on IO limits either antitrust's questions posed or its search for answers, antitrust may miss potentially relevant answers that exist or could be developed in the strategy field.

In summary, the theoretical virtues and the practical success associated with the use of IO to understand market level effects has led IO to be the dominant social science paradigm in antitrust law. As the dominant paradigm, IO has also been deployed to interpret and predict individual firm conduct which is the domain of the strategy field. Despite considerable overlap between the fields, the strategy field provides a distinct set of perspectives, theories, and empirical knowledge that reinforces, complements, and sometimes challenges antitrust

${ }_{25}$ See, e.g., Jason P. Davis \& Kathleen M. Eisenhardt, Rotating Leadership and Collaborative Innovation: Recombination Processes in Symbiotic Relationships, 56 ADMIN. SCI. Q. 159 (2011).

26 Many economic historians (for example, those studying medieval guild practices) engage in case studies, but they may not need to develop refined interview and observation techniques. 
positions based on IO. Section III examines, within the merger context, several specific examples of distinct contributions the strategy field offers.

\section{THE VALUE OF STRATEGY TO ANTITRUST: THE CASE OF HORIZONTAL MERGERS}

Section III examines the value of strategy for antitrust merger review. Regardless of the specific dimension of the merger at issue, taken collectively, the six analyses that follow underscore how the role that strategy does or can play in merger analysis must be understood, whether explicitly or implicitly, with reference to IO. The Horizontal Merger Guidelines (Guidelines), jointly revised and reissued by the Federal Trade Commission (FTC) and the Department of Justice's Antitrust Division (DOJ) (together, the Agencies) in 2010, constitute a key point of reference within this discussion. ${ }^{27}$ This reliance reflects several factors. The vast majority of merger review activity occurs at the Agency level and the Guidelines constitute the Agencies' statement of enforcement policy. Moreover, in addition to codifying current Agency thinking regarding merger review, the horizontal merger guidelines, in their various permutations through the decades, have emerged as a highly regarded distillation of existing legal precedent as well as the frequently powerful (though technically nonbinding) influence on judicial rulings. ${ }^{28}$

\section{A. Antitrust merger law}

American antitrust law is largely codified in three statutes. The Sherman Act's sections 1 and 2 address concerted (such as price fixing) and unilateral activity (such as monopolization), respectively.9 ${ }^{29}$ The FTC Act establishes the FTC as an independent competition agency that shares civil enforcement authority with DOJ under the Sherman and Clayton

27 U.S. DEP'T OF JUSTICE \& FED. TRADE COMM'N, 2010 HoRizONTAL MERGER GuIDELINES (Aug. 19, 2010), available at http:/ / www.ftc.gov/sites/default / files/attachments / merger-review/100819hmg.pdf [hereinafter GuIDELINES].

${ }_{28}$ Hillary Greene, Guideline Institutionalization: The Role of Merger Guidelines in Antitrust Discourse, 48 WM. \& MARY L. REV. 771, 828-83 (2006) (discussing broader trends in merger guideline influence).

$29 \quad 15$ U.S.C. $\S \S 1-2(2004)$. 
Acts, but the FTC is also empowered to prosecute "unfair methods of competition." ${ }^{30}$ Most importantly, for instant purposes, is Clayton Act section 7 (as amended by the Cellar-Kefauver Act in 1950), which proscribes mergers wherein "the effect of such acquisition may be substantially to lessen competition, or to tend to create a monopoly." ${ }^{\prime 31}$

The enforcement of section 7 has involved several challenges. As with the other seminal antitrust statutes, section 7 includes many concepts that the legislature did not define and that were not amenable to easy interpretation. ${ }^{32}$ Despite the ambiguity characterizing the statute's terms, one aspect that was clear was that proposed mergers

\section{B. Horizontal Merger Guidelines}

The Guidelines describe two general theories for analyzing a merger's competitive effects. Coordinated effects theory examines whether a merger increases the likelihood that firms in the industry will coordinate their actions, for example by tacitly or implicitly coordinating prices. ${ }^{33}$ Unilateral effects theory examines whether the merged firm alone can profitably raise prices (or profitably engage in other actions that have anticompetitive consequences) post-merger. ${ }^{34}$

Antitrust merger analysis depends primarily on predictions regarding firm conduct and its consequences as opposed to assessments of prior activity. These predictions can be more accurate if the Agencies understand, from the perspective of the relevant firms, how the firms perceive their choices. Such an understanding can be guided and enhanced with the help of strategy and other business fields. ${ }^{35}$

\footnotetext{
30 15 U.S.C. $\S 45(2006)$.

$31 \quad 15$ U.S.C. $\S 18$ (1996).

32 William E. Kovacic, The Modern Evolution of U.S. Competition Policy Enforcement Norms, 71 ANTITRUST L.J. 377, 470 (2003) ("In the field of economic regulation, the antitrust laws of the United States are unique in their generality.").

33 GuIDELINES, supra note $27, \S 1$.

34 Id.

35 COLLIS \& MONTGOMERY, supra note 5, provide a strategic management framework on considerations that firms contemplating a merger should analyze. Their view integrates both economic logic and a more firm-specific resource and activity system view of firm choice.
} 
The following discussion examines six important aspects of merger analysis to illustrate the strategy field's capacity to contribute to antitrust law and policy. As discussed previously, strategy field contributions can be loosely ordered in terms of their compatibility with the IO paradigm. At one end of the spectrum are strategy teachings that are essentially applications of IO to strategy and at the other end are strategy teachings that reject IO assumptions. Examples in the middle include independent contributions of strategy that are clearly distinct from, but not necessarily incompatible with, those of IO.

1. POWER BUYERS-The Guidelines designate "powerful" buyers by their ability to "often ... negotiate favorable terms with their suppliers." As such, the presence of "powerful buyers" is a factor that could potentially mitigate a merged entity's ability to raise prices, though it is not presumed to forestall a merger's otherwise adverse competitive effects. ${ }^{37}$ The Guidelines specifically contemplate circumstances that reflect this countervailing power dynamic, such as "if powerful buyers have the ability and incentive to vertically integrate upstream or sponsor entry, or if the conduct or presence of large buyers undermines coordinated effects . ..." ${ }^{\prime \prime 8}$ As such, the Guidelines identify the need to "examine the choices available to powerful buyers and how those choices likely would change due to the merger." ${ }^{139}$

Within the merger context, the evaluation of power buyers requires general assessments regarding buyer power within the relevant market, as well as more specific determinations regarding individual buyers. IO provides valuable theory and empirical tools that help in this assessment. Economics-based mechanisms facilitate understanding the relative bargaining power between suppliers and buyers, including whether a power buyer's influence would likely affect the terms other buyers receive.

Strategy's contribution to power buyer analyses primarily complements IO, and it is particularly valuable when more complex, systemic

\footnotetext{
36 GuIDELINES, supra note $27, \S 8$.

37 Id.

38 Id.

$39 \quad$ Id.
} 
understandings are needed. Consider, for example, the cost to a buyer if it switches suppliers. These switching costs may constitute an important factor determining a buyer's leverage over a seller. Strategy's potential contributions result from its more comprehensive and firm-specific approach. Switching costs are assessed by examining factors including past switching behavior, the role of formal contracts and informal relationships, the characteristics of the product or service at issue, and information and transaction costs affecting the exchange.

A strategy-based assessment of a buyer's switching costs would typically reflect the buying firm's overall business strategy and the economic and social relationship between the buyer and its suppliers. For example, with regard to the overall business strategy, the importance of a supplier's product depends on how the buyer creates value for customers. As such, whether a buyer actually has leverage over suppliers may largely depend on the buyer's business strategy. A buyer whose competitive advantage is based on lower costs might incur quite different switching costs than a buyer whose advantage derives from superior quality. Moreover, without reference to how the firm is investing in its strategy, it may be difficult to determine switching costs based on historical data alone.

Buyer-supplier relationships are more complex if, for example, critical purchases reflect some degree of joint development or other type of interdependence. An assessment of switching costs and their implications for buyer power is likely to benefit from an in-depth understanding of such relationships. Strategy and IO will likely offer different perspectives on such relationships because the strategy field, through the influence of organizational behavior, is more likely than IO to examine the social, as well as the economic, aspects of these relationships.

To be sure, the evidentiary record for certain mergers may well contain information that would direct astute analysts to consider the connections between business strategy and switching costs and to the potential importance of social factors in buyer-seller relationships. Nonetheless, when the buyer-supplier interaction under scrutiny is complex, an awareness and integration of the teachings of the strategy field offer additional useful structure for examining and assessing switching costs and, hence, for making power buyer determinations. 
2. MAVERICK FRRS-The Guidelines explicitly recognize that a firm's competitive effects may be greater than traditional measures, such as market share, nominally suggest. Such firms are deemed "mavericks" if they "play[ ] a disruptive role in the market to the benefit of customers." A maverick firm usually has one or more important characteristics (such as its technology or business model) that lead the firm to act more competitively than the other firms in the market. ${ }^{41}$ The Agencies, therefore, "consider whether a merger may lessen competition by eliminating a 'maverick' firm." ${ }^{42}$ Mergers involving mavericks are deemed relatively more problematic than those not involving mavericks.

Whether, or to what extent, a firm's activities are competitively disruptive within a given marketplace constitutes the type of marketbased analysis for which IO is well-suited. In addition to such marketlevel assessments, IO-based analysis would rely heavily on assessing historic firm behavior as part of any inquiry regarding mavericks. Ideally, these historical observations will be interpreted in light of the firm's underlying business rationale. This point was made by Professor Leslie Marx, a business school economist, who testified during joint FTC/DOJ hearings that "[t]he [G]uidelines seem to view a firm's status as a maverick as some exogenously given and unchangeable characteristic of a firm. But so-called maverick behavior is a strategic decision of a firm, not an exogenous characteristic. The [G]uidelines are written as if a maverick's behavior is that of a wild animal." ${ }^{\prime 43}$

40 Id. $§ 2.1 .5$.

$41 \quad I d$.

${ }^{42}$ Id. See generally Jonathan B. Baker, Mavericks, Mergers, and Exclusion: Proving Coordinated Competitive Effects under the Antitrust Laws, 77 N.Y.U. L. REV. 135 (2002) (comprehensively analyzing the increasing attention to the role of mavericks within the merger context).

43 FTC/DOJ Horizontal Merger Guidelines Review Project, Dec. 3, 2009 Workshop, at 90, available at http://www.ftc.gov/sites/default/files /documents/public_events/horizontal-merger-guidelines-review-project /091203transcript.pdf. Former FTC Bureau of Economics Director David Scheffman specifically invokes the differing perspectives of strategy and economics regarding mavericks. FTC/DOJ Merger Workshop, Feb. 18, 2004, at 163-64, available at http://www.justice.gov/atr/public/workshops/docs/203842.pdf ("I have big arguments with hard core economists who think this maverick stuff is b.s. I, as a strategy professor, say firms choose their competitive strategies."). 
Strategy-based analysis, with its emphasis on understanding differences among firms and its in-depth analysis of actual firm strategies, would also rely heavily upon past firm behavior. But it is arguably better suited than IO to more fully plumb the significance of that history and to transcend the role of history within the broader competitive analysis, thereby allowing for better predictions when industry conditions change. This difference reflects, in part, IO's tendency to consider firms as more similar than different. Strategy's conceptual frameworks and research methods offer a more direct route, compared with IO, for assessing the presence and execution of a maverick-oriented strategy. A strategy-oriented analysis would be less reliant on evidence regarding prior conduct if, for example, the potential disruptive action was consistent with firm positioning and efforts to create and exploit its competitive advantages. Furthermore, with the type of strategy and resources identified, it is easier to connect the specific circumstances at issue to examples outside the focal market.

3. ENTRY-According to the Guidelines, a merger will not be deemed anticompetitive "if entry into the market is so easy" that market participants, either unilaterally or collectively, cannot "profitably raise price or otherwise reduce competition" compared to the premerger levels. ${ }^{44}$ Such "easy entry" is that which would be "timely, likely, and sufficient . . . to deter or counteract the competitive effects of concern. ${ }^{\prime 45}$ An important part of assessing entry is the availability of required assets. When such assets are not generally available, entry analysis typically focuses on particular firms ${ }^{46}$ In addition to historical evidence regarding entry, whether successful or unsuccessful, the Guidelines provide a list of elements characterizing potential barriers to entry and entry efforts that the Agencies will consider. ${ }^{47}$

4 GUIDELINES, supra note 27, §9 (emphasis added). "[Product r]epositioning is a supply-side response that is evaluated much like entry ...." Id. §9.

$45 \quad$ Id. $\$ 9.3$.

46 Id. $\S 9$.

47 These elements include: "planning, design, and management; permitting, licensing, or other approvals; construction, debugging, and operation of production facilities; and promotion (including necessary introductory discounts), marketing, distribution, and satisfaction of customer testing and qualification requirements." Id. 
An IO-based entry analysis focuses on the increased incentives for entry given changes in market conditions (especially anticipated price or quality changes) associated with a given merger.

The strategy field's contributions to entry analysis derive from its insights regarding such decisions within the context of firms' broader business and corporate plans. For firms specifically identified as nominally plausible entry candidates, it may be possible to better assess the likelihood of entry by determining whether it makes sense given the specific firm's overall strategy. Strategy-oriented questions include: Is entry the best use of the firm's resources? Does the firm possess or will it be able to develop and sustain competitive advantage in this market? Entry is less likely if a firm's strategy entails the use and development of particular joint resources or the development of core capabilities to which this entry would not contribute or, perhaps, from which this entry would affirmatively detract. The converse would also be true. The strategy field offers numerous frameworks, including those regarding corporate strategy and diversification, which would help illuminate the entry issues with which merger law grapples. ${ }^{48}$ Strategy-oriented considerations are, of course, not unique to a strategy field-based analysis, but most analysts trained only in IO are likely to be relatively unfamiliar with them.

4. MARKET DEFINITION AND DEMAND ESTIMATION-Market definition focuses upon "demand substitution factors" so as to "help[] specify" the product and geographic markets in which competitive issues may arise. ${ }^{49}$ More specifically, it examines "customers' ability and willingness to substitute" the merging firms' products with those of other firms. Ideally, the relevant product and geographic markets will be defined to include "reasonably interchangeable" substitutes with regard to "product attributes and perceptions" and geographic location, respectively. ${ }^{50}$ Such definitions better enable the Agencies to identify market participants, and by implication market shares and

${ }_{48}$ A resource-based view of diversification would, for example, analyze whether entry makes sense given the joint resources developed and used across a firm's entire portfolio of businesses. See Collis \& MONTGOMERY, supra note 5 .

4 GUIDELINES, supra note $27, \S 4$.

50 Id. 
concentration, which often helps illuminate a merger's "likely competitive effects." ${ }^{51}$ The Guidelines do not require that Agency analysis begin with market definition and they specifically indicate that certain of their analytical tools "do not rely on market definition." 52 Nonetheless, they state that the "evaluation of competitive alternatives available to customers is always necessary at some point in the analysis. ${ }^{.53}$

IO and other fields within economics have developed many theories and methods to facilitate characterizing and measuring market demand. With limited exceptions, these approaches treat consumer preferences as fixed. In contrast to these economic fields, business fields such as marketing treat consumer preferences as more malleable and their choices as more subject to cognitive biases and the use of heuristics. The divergence in assumptions regarding consumer preferences and choices likely reflects factors including the strong disciplinary influence of psychology on the business fields and perhaps the business problems encountered in practice (such as creating effective advertising programs). Consequently, marketing scholarship offers many distinctive theories and methods that are not closely related to those of $\mathrm{IO}^{54}$

Differences between marketing and IO perspectives on consumer preferences and choice may manifest themselves in both assessments of qualitative evidence and in econometric measurements of demand. With respect to qualitative evidence, one practical consequence of this difference is that the relative willingness to credit the testimony of industry experts may depend upon the experts' treatment of consumer preferences. In terms of measurement, marketing scholarship suggests it would be important for antitrust analysis to understand the conditions under which endogenous preferences and cognitive biases are first-order as opposed to second-order considera-

\footnotetext{
$51 \quad I d$.

$52 \quad I d$.

$53 \quad$ Id.

54 While the behavioral economics subfield imports and develops psychology-based insights, this subfield's teachings have not yet been substantially integrated into $\mathrm{IO}$.
} 
tions. ${ }^{55}$ Of particular interest would be an exploration of how allowing for endogenous preferences and cognitive biases change the predictions of econometric models used to estimate the competitive effects of mergers.

Teachings from the strategy field, though less directly applicable than marketing to consumer demand applications, help inform antitrust analysis in contexts where the buyers are firms. For example, firm strategies may be quite informative regarding substitution patterns and perhaps even short-to-medium term changes in preferences due to modifications in a buyer's strategy given changes to its downstream output market.

5. EFFICIENCIES-The Guidelines recognize that "a primary benefit of mergers to the economy is their potential to generate significant efficiencies and thus enhance the merged firm's ability and incentive to compete ... ." ${ }^{56}$ For the FTC and DOJ to "credit" an efficiencybased defense, the efficiencies must be "cognizable" in that they are merger-specific, verifiable, and do not reflect "anticompetitive reductions in output or service." ${ }^{\prime 57}$ This requires that the claimed efficiencies are likely to be achieved with the proposed merger, or a comparably anticompetitive means, and that they are unlikely to be achieved otherwise. The Agencies consider alternatives that are "practical," not those that are merely "theoretical," in their assessments. ${ }^{58}$ The merging parties, who possess the information most relevant to efficiency claims, must substantiate their efficiency claims notwithstanding the fact that they are oftentimes "difficult to verify and quantify." ${ }^{59}$

55 Marketing and economics literature addressing consumer preference learning models includes, respectively, Gregory S. Carpenter \& Kent Nakamoto, Consumer Preference Formation and Pioneering Advantage, 26 J. MARKETING RES. 285 (1989), and Michael J. Dickstein, Efficient Provision of Experience Goods: Evidence from Antidepressant Choice (Stanford University Working Paper, Apr. 2014).

56 GUIDELINES, supra note $27, \S 10$.

57 Id.

$58 \quad$ Id.

59 Id. 
IO provides many tools that facilitate the assessment of efficiency claims, particularly those claims involving measurable production cost efficiencies (such as scale and scope efficiencies), network economies, savings from adopting the superior method of one of the merging parties, and savings from eliminating duplication of functions. Many of these economies, especially those relating to production, can be estimated using engineering cost estimates.

An important window into Agency treatment of efficiencies, specifically at the FTC, is provided by a staff report from the FTC's Bureau of Economics. Authors Malcolm B. Coate and Andrew J. Heimert usefully characterize the efforts and conclusions arrived at by the FTC's staff within the Bureau of Economics and Bureau of Competition from 1997 to 2007 regarding alleged merger efficiencies. This report concluded that both staffs "did a thorough job of acknowledging and considering the parties' efficiency claims." ${ }^{\prime 60}$ Significantly, the report also concluded that during the decade in question "little appears to have changed with the types of the parties' efficiency claims or the staff's treatment of them" and that "both [the Bureau of Competition] and [the Bureau of Economics] . . did not make conclusive recommendations concerning a majority of efficiency claims they considered."

Two characteristics that decrease the reliability associated with efficiency claims are that many such claims depend on proposed investment plans being undertaken post-merger and that the organizational costs associated with merger integration are frequently underestimated by the merging parties and difficult to quantify. ${ }^{62}$ Furthermore, estimates regarding the existence and feasibility of less restrictive alternatives may be incomplete. These concerns may par-

60 Malcolm B. Coate \& Andrew J. Heimert, Merger Efficiencies at the Federal Trade Commission 1997-2007, at vi (FTC Bureau of Economics Report, Feb. 2007) available at http:/ / www.ftc.gov/sites/default/files/documents / reports/merger-efficiencies-federal-trade-commission-1997-2007/0902 mergerefficiencies.pdf.

$61 \quad$ Id.

62 Ulrike Malmendier \& Geoffrey Tate, Who Makes Acquisitions? CEO Overconfidence and the Market's Reaction, 89 J. OF FINANCIAL ECONOMICS 20 (2008), for example, find evidence supporting that overpayment for acquisitions is caused by CEO overconfidence. 
tially explain the conservative manner with which antitrust law treats merger efficiency claims.

Strategy research offers some promising directions to address these problems. The strategy literature provides deeper knowledge regarding firm-specific factors identified in IO-based efficiencies evaluations as well as a means to understand factors that are either underappreciated or less well-understood by IO. ${ }^{63}$ For example, strategy provides a system-level understanding regarding how different activities within the firm reinforce each other and impact competitive advantage. More concretely, strategy often provides a superior basis, relative to $\mathrm{IO}$, for evaluating somewhat imprecise managerial statements regarding a merger's purpose and the likely path of the merged firm's investment and strategy development.

Integration costs and implementation feasibility issues are critical to understanding organizational change, a central research concern of the organizational behavior and strategy fields. Work in this area can highlight where the largest opportunities and challenges would lie with respect to aligning and integrating the acquired firm and, therefore, would assist in understanding the "cost" side of the net efficiencies estimation. ${ }^{64}$ If developed within the context of merger review, such insights would allow for a more nuanced view of efficiencies which might, in turn, lead to more refined treatment of this critical aspect of mergers ${ }^{65}$

${ }_{63}$ See Malcolm B. Coate, Efficiencies in Merger Analysis: An Institutionalist View, 13 SUP. CT. ECON. REV. 189 (2005) (advocating incorporation of "institutionally-based business strategy analysis to both evaluate efficiencies and competitive concerns").

${ }_{64}$ One example that highlights the difficulties in integration is the knowledge problem that firms experience when trying to transfer best practices from one of their plants to another. See, e.g., Szulanski, supra note 13.

${ }_{65}$ Given that the strategy literature's frameworks and evidence offer particular value to antitrust assessments concerning individual firms, strategycan help inform understandings regarding remedial measures including, for example, divestitures. The practical consequences of proposed divestitures often turn upon the extent to which the acquiring firm's strategy will support the meaningful integration and exploitation of the firm or assets at issue. This information forces a consideration of the totality of forces affecting likely buyer firm decisions, which can be critical for transcending the possibilities suggested by economic analysis, especially when existing business documents and managerial opinions are contradictory and confusing. 
Finally, the merger-specificity requirement regarding efficiencies often entails an examination of alternatives to the proposed merger to achieve the efficiencies. Such assessments inevitably entail some degree of judicial or Agency second-guessing of firms. ${ }^{66}$ Basic $I O$ analysis is helpful here, but so too is a strategy analysis. Assessing alternative approaches requires determining whether the merging parties have the capabilities to reasonably undertake the alternative, whether the alternative fits into the overall strategy of the firm, and whether various implementation obstacles would or did prevent the proposed alternative from being adopted. Answers to these questions fall within strategy's domain.

6. INNOVATION-Consumer welfare, as defined in the Guidelines, concerns not only static considerations of price and quantity but also the dynamic consideration of innovation. Because "[c]ompetition often spurs firms to innovate," it is important to "consider whether a merger is likely to diminish innovation competition $\ldots . .{ }^{67}$ Curtailed innovation could manifest itself through reduced incentives to initiate new product development or to continue existing product-development efforts. ${ }^{68}$ While the significance, at least in theory, of innovation considerations within merger analysis is longstanding, its actual treatment remains challenging particularly within technologically dynamic markets. ${ }^{69}$

${ }_{66}$ See, e.g., FTC v. Cardinal Health, 12 F. Supp. 2d 34 (D.D.C. 1998). The district court found that the FTC's evidence "strongly suggests" that "much" of alleged merger-related savings could be obtained without merging through "improved purchasing practices and inventory reductions on their own by adopting better business strategies." $I d$. at 63 . The court ultimately ruled that the claimed procompetitive efficiencies did not outweigh the likely anticompetitive effects associated with the merger. See also Coate \& Heimert, supra note 60, at 24 (noting that the Bureau of Economics staff's first and second most common questions regarding efficiency claims concerned their verifiability and merger specificity, respectively).

67 GuIdELINES, supra note $27, \S 6.4$.

$68 \quad I d$.

69 Id. See also Dennis A. Yao \& Susan S. DeSanti, Innovation Issues Under the 1992 Merger Guidelines, 61 ANTITRUST L.J 506 (1993). In the mid-1990s the Agencies sought to define "innovation" markets as a way to assess the innovation effects of mergers. See, e.g., Richard J. Gilbert \& Steven C. Sunshine, Incorporating Dynamic Efficiency Concerns in Merger Analysis: The Use of Innovation Markets, 63 ANTITRUST L.J. 569, 601 (1995); Ilene Knable Gotts \& 
One significant obstacle to $\mathrm{IO}$ as a vehicle to more meaningfully incorporate dynamic efficiency considerations into merger analysis is the field's incomplete understanding of the sources of innovation. Economists, for example, disagree about what market structure induces the most innovation and even what constitutes the optimal level of innovation. ${ }^{70}$ Work in the field involves topics such as innovation incentives, knowledge spillovers, and the impact of property rights. There is less work on innovation processes themselves.

The strategy, marketing, and operations management fields also have an incomplete understanding of innovation. However, their approaches to understanding the innovation process and innovation strategy differ significantly different from those of IO. This reflects, in part, their focus on processes within individual firms and firm-level decision making, as well as these fields' relative openness to noneconomic approaches, including those of sociology, psychology, organizational studies, and the history of science and technology. Because the business fields tend to be multidisciplinary, they offer perspectives that IO arguably underappreciates, such as viewing firm knowledge about innovation as relevant capabilities embodied in organizational routines.

As an example of such approaches' potential value, consider the application of the strategy field's resources and capabilities frame-

Richard T. Rapp, Antitrust Treatment of Mergers Involving Future Goods, ANTTTRUST, Fall 2004, at 100, 102. The difficulties associated with this approach generally limited its use to very specific settings such as the pharmaceutical drug industry where regulatory constraints make predictions of future drug markets quite reliable. See, e.g., Hillary Greene, Non-Per Se Treatment of Buyer Price-Fixing in Intellectual Property Settings, 2011 DuKE L. \& TECH. REV. 4, III 61-62.

70 Former FTC Chairman Timothy Muris and co-author Bilal Sayyed argued against inclusion of any reference to "innovation markets" within the merger guidelines given the paucity of understanding and the narrowness of Agency experience regarding their operation. They were equally wary of the inclusion of a section on innovation more generally. See Timothy J. Muris \& Bilal Sayyed, Three Key Principles for Revising the Horizontal Merger Guidelines, ANTTRUUST SOURCE, Apr. 2010, at 12, and id. at 13 (("Theoretical and empirical work in economics has not found a conclusive relationship between concentration levels and the pace or amount of innovation."). See also Richard Gilbert, Looking for Mr. Schumpeter: Where Are We in the Competition-Innovation Debate?, in 6 INNOVATION POLICY AND THE ECONOMY 159, 205-06 (Adam B. Jaffe et al. eds., 2006). 
work to merger analysis when innovation competition is at issue. ${ }^{71}$ Could the competitive consequences of a merger between firms with overlapping innovation capabilities be better predicted by considering firm capabilities rather than by assessing market competition in current markets $?^{72}$ Stated alternatively, rather than focusing on whether specific innovations may arise post-merger, would more useful predictions result from analyses that focused on the processes that produce that innovation and which, if any, firms possess key capabilities for innovation in particular areas?

Strategy teaches that firms are likely to be more effective (future) competitors if they possess the resources and capabilities needed to serve the projected future market. While intuitively appealing, the value of a capabilities approach within the merger context would need to be established empirically. Studies could, for example, explore the relationship between various types of capabilities and innovation in identifiable areas (and an absence of innovation in those areas by firms who do not possess these capabilities) as well as boundary conditions for the application of this approach.

\section{THE INFLUENCE OF THE STRATEGY FIELD ON ANTITRUST: AN UPDATE}

Section III explored the strategy field's distinctive ability to contribute to antitrust law and policy within the merger context. Though framed within the context of Agency application of the Guidelines, the discussion underscored the value of strategy-based concepts, as well as concepts drawn from other business fields, to enhance antitrust decision making more generally. Over time, numerous commentators have also advocated antitrust's greater reliance upon various business fields. Despite their varied approaches and positions, collectively understood these commentators suggest that antitrust law inadequately accounts for business fields including strategy. ${ }^{73}$

7l See, for example, David J. TeEce, DyNamic Capabilities \& STRategic MANAGEMENT: ORGANIZING FOR INNOVATION AND GROWTH 48 (2009), for a discussion of capabilities useful for innovation.

72 Yao \& DeSanti, supra note 70, at 511.

73 See supra note 2. A number of symposia (American Antitrust Institute 
In 2010, strategy professors Felix Oberholzer-Gee and Dennis A. Yao sought to more systematically, albeit imperfectly, assess strategy's influence on antitrust through a first-order citation analysis of judicial rulings and legal scholarship from 1999-2008 ${ }^{74}$ Briefly restated, Oberholzer-Gee and Yao first identified a small group of prominent scholars, top journals, and core concepts in each of the strategy and IO fields..$^{75}$ These scholars, journals, and concepts were used as the "targets" of potential citations. The "sources" of the citations were all federal and state antitrust cases and law reviews on antitrust law indexed by the LexisNexis Academic database. The citation counts were the number of sources that reference the identified citation targets. On the basis of these counts, Oberholzer-Gee and Yao concluded that "strategy has had a minimal effect on thinking in antitrust."

Section IV extends that analysis through 2013, provides citation rates calculated by dividing the absolute number of citations by the total number of potential sources of citations, ${ }^{7}$ and offers some additional information regarding merger cases and the influence of the marketing field. ${ }^{78}$ The updated analysis reinforces the overall conclusion Oberholzer-Gee and Yao reached five years ago. As measured by citation counts, the strategy field's influence on antitrust law and scholarship appears small in

2002, 2013) and panels (ABA Antitrust Section magazine 1998 and 2006; ABA spring meetings; FTC and DOJ hearings) have addressed this general issue.

74 Oberholzer-Gee \& Yao, supra note 2.

75 Id. The citation approach was also applied in William $\mathrm{E}$. Kovacic, The Influence of Economics on Antitrust Law, 30 ECON. INQUIRY 294 (1992) to assess the influence of economics on antitrust law.

76 Oberholzer-Gee \& Yao, supra note 2, at 1475.

$\pi$ The percentage of unique cases or law reviews that mention a key term is smaller than that reported, as many cases and law reviews mention multiple key terms.

78 The current analysis differs somewhat from the Oberholzer-Gee \& Yao analysis, supra note 2, because the instant analysis used WestLaw (as of May 2014) and focused solely upon federal cases. One of the issues associated with determining relevant citations is whether the case or article has a substantial antitrust component. Here we designate an article as an antitrust article if "antitrust" is mentioned ten or more times. This threshold was chosen after an examination of the articles that would have been included or excluded if a lower or higher number of mentions, respectively, had been adopted. 
absolute terms and dwarfed relative to IO. The most recent five-year period is largely consistent with the preceding years with one exception: The increase in citation of strategy concepts is substantially higher in the 2009-13 period. This count could reflect strategy's increasing influence, but a more in-depth study is required before drawing any conclusions. ${ }^{79}$

A specific analysis of federal merger cases reveals a pattern of citations similar to that in the antitrust case analysis but with a generally higher citation rate..$^{30}$ Given that the number of citations in merger cases is quite modest, one cannot draw any strong merger-specific conclusions based on these statistics. A citation analysis was also undertaken to examine the influence of the marketing field on antitrust law, and thereby provide a reference point against which to gauge whether the strategy field was an outlier in terms of business field influence on antitrust. The analysis used marketing scholars and marketing journals as citation targets and produced measures of citations that, relative to strategy, were smaller in terms of citations to marketing scholars but roughly similar in terms of citations to marketing journals. ${ }^{81}$ This evi-

79 A closer look at the data shows that this increase is largely composed of references to "disruptive technology" and "value chain." The increase in references to disruptive technology is mirrored by an increase in citations to Clayton Christensen, who pioneered the disruptive technology concept. CLAYTON CHRISTENSEN, THE InNOvator's Dilemma (1997). Because "hot" concepts change over time, it is unclear if this increase reflects a greater openness to strategy generally or merely reflects a particular idea that has gained traction. While this increase is somewhat encouraging, the preliminary assessment regarding the influence of other foundational concepts in strategy is mixed.

so There are no citations between 1999 and 2013 to our target strategy scholars and journals and only two citations to the targeted strategy concepts. From 1999 to 2003 there were 2 citations of the targeted economics scholars, 2 for the targeted economics journals, and 5 for the targeted economics concepts. The comparable numbers were 2 (scholars), 2 (journals), 3 (concepts) and then $0,0,7$, for 2004-08 and 2009-13, respectively. Because the baseline numbers of merger cases were 102, 76, and 67, for the periods 1999-2003, 2004-08, and 2009-13, respectively, the percentage of citations was considerably higher for mergers than within other antitrust contexts. This result is unsurprising given that merger analysis can involve extensive and broad-ranging economic analysis.

81 An analysis of citations to a selected list of ten distinguished marketing scholars (based on awards for marketing scholarship) and four marketing journals (Journal of Consumer Research, Journal of Marketing Research, Journal of Marketing, and Marketing Science) was also undertaken. The ten distinguished scholars 
dence arguably suggests that the strategy counts are probably representative of the general level of influence of business fields on antitrust.

As measures of influence, both the absolute numbers of citations and the citation rates reported in tables 2 and 3 have many limitations, and therefore should be interpreted as merely suggestive. The most important limitation is that the citation count is based on a small selection of targets. A small absolute number of citations increases the possibility that the targets are unrepresentative of their respective

\section{Table 2}

Target Citations in Federal Court Rulings (1999-2013)

\begin{tabular}{lllllll} 
& \multicolumn{2}{c}{ 1999-2003 } & \multicolumn{2}{c}{ 2004-08 } & 2009-13 \\
Strategy & & & \multicolumn{1}{c}{ Citation \# } & Citation \% & Citation \# Citation \% & Citation \# Citation \% \\
Scholar & 0 & 0 & 0 & 0 & 0 & 0 \\
Journal & 0 & 0 & 1 & 0.1 & 0 & 0 \\
Concept & 3 & 0.3 & 0 & 0 & 4 & 0.3 \\
IO Economics & & & & & \\
Scholar & 10 & 1.1 & 8 & 0.7 & 7 & 0.6 \\
Journal & 6 & 0.7 & 10 & 0.9 & 5 & 0.4 \\
Concept & 30 & 3.3 & 30 & 2.6 & 36 & 3.0 \\
\hline
\end{tabular}

Table 3

Target Citations in Law Reviews (1999-2013)

$$
\text { 1999-2003 2004-08 2009-13 }
$$

Citation \# Citation \% Citation \# Citation \% Citation \# Citation \%

Strategy

Scholar

63

3.2

2.7

56

2.4

73

2.8

Journal 54

2.7

41

1.8

67

2.6

Concept 53

45

$2.0 \quad 109$

4.3

IO Economics

\begin{tabular}{lllllll} 
Scholar & 514 & 25.8 & 437 & 18.9 & 472 & 18.4 \\
Journal & 623 & 31.3 & 633 & 27.4 & 737 & 28.7 \\
Concept & 558 & 28.0 & 565 & 24.5 & 613 & 23.9 \\
\hline
\end{tabular}

in total received fewer than ten citations in law reviews in each five-year period. The four marketing journals received, in total, roughly the same average number of citations as the top three strategy journals in each five-year period. 
groups, and hence would provide misleading statistics. That problem is of least concern with respect to the journal citation count because the top journals would seem both representative and relatively inclusive, but it is of greater concern with respect to the scholar citations. ${ }^{82}$ Another challenge with the scholar counts is that the individuals are chosen by achievement that is field-based (such as influence on IO economics) rather than antitrust law-based (that is, influence on antitrust law). This selection criterion focuses on the diffusion of big ideas from each field and presumes that the ideas would be captured through references made by scholars who are more directly engaged with antitrust. ${ }^{83}$ Despite this caveat regarding scholar choice, it appears that the scholar, journal, and concept counts tell a relatively consistent story within the strategy field and IO categories.

Comparisons across the strategy field and IO categories should also be made cautiously. For example, the absolute numbers do not adjust for the difference in the number of antitrust topics for which the IO and strategy literatures are relevant. For example, the strategy literature has comparatively less to offer than IO on topics such as predicting the price effect of a merger. Finally, it is possible that some strategy-based ideas will influence antitrust through IO scholarship but that the connection may be obscured because the fields use different terminology to articulate the same or similar ideas.

${ }_{82}$ The targeted journals in IO included a general journal (American Economic Review) that publishes articles relevant to the field and two top field journals (RAND Journal of Economics and Journal of Industrial Economics). The targeted journals in the strategy field included a general journal (Harvard Business Review), the top strategy field journal (Strategic Management Journal), and the top organizational management journal (Administrative Science Quarterly). In this analysis, unlike Oberholzer-Gee and Yao, we counted citations to Harvard Business Review only if the article was clearly strategy oriented.

83 The list of targeted scholars was based on prominence in the field, such as Nobel Prizes and Bates Clark medals in economics with recognized contributions to IO and mention in top strategy "guru" lists, and is intended to be representative of top producers of ideas in their respective fields. There are many well-known scholars who have a substantial portion of their research directed to antitrust law or have been very active as expert witnesses. These scholars generate higher citation rates in the antitrust literature, but present more difficult interpretation issues and arguably a less reliable baseline for cross-year comparisons. 


\section{DIFFUSION OF STRATEGY FRAMEWORKS AND CONCEPTS TO ANTITRUST}

We have argued that the strategy field appears to have influenced antitrust law and policy to a lesser extent than warranted. Section $V$ explores the diffusion of strategy frameworks and concepts into antitrust, with a particular emphasis on obstacles to such diffusion. ${ }^{84}$ We first examine how the characteristics of the strategy field's content affects idea adoption in antitrust and then explore the conduits through which its ideas may flow. Finally, we conclude with more general considerations regarding the relationship between the strategy field and antitrust going forward.

\section{A. Content: Characteristics and idea adoption}

Despite the strategy field's potential to augment antitrust analysis, certain of the field's characteristics have impeded the diffusion and adoption of its ideas. These include strategy's focus on firm rather than market- or industry-oriented problems, its focus on explaining profits rather than welfare outcomes, and the lack of strong consensus regarding what factors are most important for explaining firm behavior and profitability. Consequently, strategy's direct influence on antitrust appears to have been relatively weak. Ironically, some of the very characteristics that enable the strategy field to contribute to antitrust discourse also appear to have diminished its influence.

- STRATEGY IS MOST USEFUl FOR FIRM- RATHER THAN MARKET-LEVEL DETERMINATIONS: The extent to which a scholarly field influences legal discourse depends, in part, on the extent to which the field's core concepts are both substantively relevant and sufficiently amenable to incorporation within the legal system. Antitrust's primary objective is to promote market competition. Pursuit of this objective requires knowledge of how markets perform and what factors influence competition. This knowledge is a primary focus of IO. ${ }^{85}$ In contrast, the

si Spencer Weber Waller provides a very thoughtful discussion, which spans the twentieth century, regarding the "many interlocking reasons why business discourse has always taken a back seat to economic discourse in the formulation and enforcement of antitrust policy." Waller, supra note 2, at 311. See also Oberholzer-Gee \& Yao, supra note 2.

${ }^{85}$ See generally Peter C. Carstensen, Antitrust Law and the Paradigm of Industrial Organization, 16 U.C. DAVIS L. REV. 487, 492-504 (1983). Carstensen 
strategy field focuses on firms more than markets and generally emphasizes questions relating to the creation of competitive advantage through the configuration, development, and use of a firm's resources. More generally, IO focuses on the main market performance question posed in an antitrust determination while strategy focuses on questions that illuminate components of that main question.

- StRategy focuses ON PROFITS, NOT WElfare: A field's contribution to legal developments also depends on whether the field's insights are tailored to addressing the questions that legal issues pose. Strategy insights generally have not been either conceived or developed in ways that directly reflect the welfare concerns of antitrust law. ${ }^{86}$ In contrast to IO, the strategy field is oriented toward assessing the implications of firm behavior for firm performance rather than for social or consumer welfare. The lack of any significant effort to extend or otherwise translate insights regarding firm performance to address social welfare concerns has, therefore, likely impeded the influence of these ideas on the antitrust community. ${ }^{87}$

- Strategy, AS A FIEld, lacks STRONG INTERnAl CONSENSUS: The influence of a social science theory on the law typically increases if the theory is widely accepted within its field. As a multidisciplinary field, strategy offers a variety of approaches to understanding complex phenomena. This diversity, as reflected by its many schools of thought, has generated strong internal debates regarding the relative importance of even factors that the strategy field as a whole has identified as contributing to firm behavior and firm performance. While such debates may create a healthy atmosphere for scholarly progress, they may also complicate and potentially impede the incorporation of strategy teachings into antitrust law. ${ }^{88}$

provides an excellent analysis of the relationship between IO and antitrust. He characterizes IO's reliance upon microeconomic theory and analysis of industry and firm behavior as having a "focus [that] corresponds closely to the issues of antitrust concern." Id. at 492. This development was "not surprising," according to Carstensen, since the economists who developed IO were "very interested in the antitrust laws." Id. at 492 n.24.

86 But see R. Edward Freeman, Strategic Management. A STAKeholder APPROACH (1984).

87 See, e.g., Oberholzer-Gee \& Yao, supra note 2.

ss Cf. Waller, supra note 2, at 311-12 (noting that diversity of views characterizing "academic business theory" and, as a consequence, the absence of any "single business discourse that an antitrust outsider could readily identify and master ... to unseat the dominant economic language in antitrust"). 
In contrast, IO has much greater within-field consensus, arguably because of the field's relative maturity and the dominance of core disciplinary assumptions from economics.

\section{B. Conduits: Path dependence and idea adoption}

The influence of a particular scholarly field on the law reflects not only the intrinsic characteristics of the field's teachings and their relevance to the key legal problems, but also the conduits for transmitting those teachings. A principal conduit for the flow of ideas in antitrust law is the members of its community who, in turn, are exposed to various ideas depending on their training and the frameworks through which they understand antitrust problems.

For the purpose of understanding the speed and adoption of strategy field ideas, it is important to recognize that IO had been adopted as the main social science foundation for antitrust long before strategy matured as an academic field. ${ }^{89}$ By the 1990s, when the strategy field had matured with its own distinct body of knowledge, antitrust case law and policy discussions already reflected the structure of IO principles. Moreover, both academic and practicing lawyers viewed antitrust law and policy through IO frameworks and IO economists had become an integral part of the antitrust community.

Given IO's relative dominance in antitrust, the flow of strategy ideas to antitrust has depended in large part on the exposure of IOoriented antitrust participants to strategy field ideas. One potentially important channel for exposure involves economics scholars within business schools or strategy departments who teach or research strategy topics. Over the last two and a half decades, several such economics scholars have assumed leadership positions in the federal antitrust

s9 The strategy field's major journal did not launch until 1980 . To be sure, many of the concepts that fall under the umbrella of strategy developed within the context of general management or business policy in the academic world and at various strategy consulting firms. See MARC AlLEN EISNER, ANTITRUST AND THE TRIUMPH OF ECONOMICS: INSTITUTIONS, EXPERIENCE, AND POLICY CHANGE (1991). Eisner argues that the integration of economists into the Agencies resulted in "an institutional transmission belt" that connected the Agencies with $\mathrm{IO}^{\prime}$ s intellectual developments. $I d$. at 18 . 
agencies, ${ }^{90}$ and many more have served as experts on antitrust matters. Such individuals have generally had a greater exposure to strategy and management insights relative to their economics department counterparts, and constitute likely conduits for diffusion of such knowledge. Another channel for incorporating strategy the testimony of business experts. Such testimony has the potential to prompt further investigation into various strategy-oriented theories, especially when IO-oriented explanations are unavailable or unsatisfying.

For strategy ideas to influence the antitrust community, there must be not only exposure, but also openness to the ideas. Whether members of the IO-influenced antitrust community respond to strategy ideas depends on a number of factors. As discussed, one factor is the compatibility between the strategy idea and IO. One would expect, for example, greater receptivity when the ideas are compatible with IO (because, for example, they derive from common assumptions) than when they are not. Another factor is the level of translation of terms and concepts as well as further development that might be necessary for the importation of ideas. Along these lines, one might expect that some ideas originating in or inspired by the strategy field will be developed and then adopted in the more familiar IO form. Following this logic of idea diffusion, the indirect translation and development path may prove to be an effective means by which strategy ideas, especially those complementary to IO, are adopted by antitrust law.

\section{Future influence}

If members of the antitrust community are the primary conduits for strategy ideas, then IO's dominance should not necessarily impede strategy's influence as long as its ideas do not conflict with those of IO. But, if the strategy ideas at issue conflict with IO, or perhaps are merely foreign to IO, some resistance may ensue. Stated alternatively, complementary ideas (such as understanding of singlefirm actions, efficiencies, and remedies) would likely receive the least resistance, whereas substitute ideas (such as theoretical ideas or empir-

90 Economists in antitrust agency leadership positions who have taught in business schools or have taught strategy, or both, include Jonathan B. Baker, Jeremy I. Bulow, Michael L. Katz, David Scheffman, Fiona M. Scott Morton, Carl Shapiro, and Dennis A. Yao. 
ical findings that directly challenge conventional economic understandings of markets and firm behavior) would likely encounter the most resistance.

As a source of complementary ideas and frameworks that facilitate deeper and more comprehensive interpretations of evidence, the further adoption of strategy teachings would seem a natural progression for antitrust law and policy. ${ }^{91}$ In the merger context, for example, we have illustrated how strategy and other business fields can enhance analyses as well as help illuminate tough antitrust policy questions by challenging existing wisdom and offering alternative approaches. Strategy's provision of a more nuanced set of frameworks for understanding strategic choice regarding maverick activity or market entry constitute examples of the former, while the potential use of competencies in assessing the implications of a merger for innovation illustrates the latter. Moreover, we believe that strategybased insights will likely become increasingly important as key antitrust determinations shift from industries characterized by simpler production relationships, such as economies of scale, to those industries characterized by complex innovation systems.

Unless the strategy field finds its own voice in antitrust matters, it will likely remain somewhat beholden to IO economists and IO-oriented antitrust lawyers to identify and translate relevant strategy teachings. One factor that would facilitate independent influence would be the more conscious pursuit of overlapping research agendas between the strategy and antitrust communities. Thus far, their shared interests largely mirror the IO-strategy overlap. The strategy field itself has not prioritized antitrust-related questions, nor has the antitrust community substantially engaged the strategy community. Even if there is no

91 While the introduction of some knowledge from the strategy literature seems clearly beneficial in terms of improving case-specific understandings, one should recognize that incorporating this knowledge could lead to less predictability and greater enforcement expense. A similar concern has engendered a major debate in the antitrust community with regard to the introduction of increasingly more sophisticated and subtle economic theories into antitrust analysis. The addition of business field concepts would have a similar effect, though with the added complication that some of the business field concepts may conflict with economic ideas already reflected in the antitrust law canons. 
change in strategy's substantive focus per se, the field of strategy can still be more mindful of the antitrust community as an important audience. At a minimum, strategy as a field should more directly manage its literature's transmission and translation so as to facilitate the antitrust community's awareness, understanding, and possible use of strategy's insights.

An important and possibly more effective avenue, albeit more indirect, through which strategy can contribute is the antitrust community's increasing interest in the implications of deviations from rationality in decision making. In recent years, for example, many long-standing concerns regarding bounded rationality and nonoptimizing decision making have reemerged under the banner of applying behavioral economics and psychology to antitrust. ${ }^{92}$ We believe that the strategy field is particularly well suited to contribute within this context given its broad multidisciplinary foundation and its welldeveloped knowledge of the role of behavioral factors on firm decision making. The strategy literature, as well as that of marketing and other business fields, therefore provides excellent starting points from which to infuse behaviorally motivated research into the issues relevant to antitrust law.

92 See generally Avishalom Tor, Understanding Behavioral Antitrust, 92 TEX. L. REV. 573, 576-77 nn.7-10 (2013) (delineating in great detail numerous articles (including dedicated journal symposia), academic and professional panels, and enforcement agencies and officials that "debate the merits and demerits of behavioral antitrust"); Christopher Leslie, Can Antitrust Law Incorporate Insights from Behavioral Economics?, 92 TEX. L. REv. 53 (2014) (providing a useful commentary on Tor's thoughtful article); James C. Cooper \& William E. Kovacic, Behavioral Economics and Its Meaning for Antitrust Agency Decision Making, 8 J.L. ECON. \& POL'Y 779, 781 (2012) (applying bounded rationality and other behavioral economics-related concepts to the antitrust agencies to better understand these agencies and their personnel); Joshua Wright \& Judd E. Stone II, Misbehavioral Economics: The Case Against Behavioral Antitrust, 33 CARDOzo L. REv. 1517, 1548 (2012) (arguing "behavioral antitrust is not ready for prime time"); Maurice E. Stucke, Behavioral Economists at the Gate: Antitrust in the Twenty-First Century, 38 LoY. U. CHI. L.J. 513, 515 (2007) (lamenting the absence of any federal court antitrust rulings citing behavioral economics at the time of publication). The literature is voluminous and growing though, unfortunately, not in the manner we prescribe. 


\section{CONCLUSION}

Antitrust law's development, particularly in recent years, has been one of increasing solicitude to the complexities of competition. Broad swathes of conduct previously judged under a per se standard are now subject to a rule of reason analysis. Heavy, at times dispositive, reliance on gross market structure measures such as concentration has transitioned to more complicated theories of strategic interaction that reflect some of IO's progress in understanding the mechanisms of competition.

Such increased attention to the underlying mechanisms that explain market outcomes, in turn, has increased the need for more indepth understanding of firm behavior. IO has fueled much of this increased attention and, in particular, has offered valuable insights concerning competitive dynamics that shape market outcomes. IO has been less successful, however, in providing sufficiently nuanced understandings of firm behavior, the primary domain of research by business fields such as strategy.

Both the opportunity and the need exist for antitrust law and scholarship to better incorporate knowledge regarding firm behavior from business fields such as strategy. Leveraging strategy-based insights that are largely complementary to IO should be comparatively straightforward. The bigger challenge may lie with the antitrust community's willingness to engage seriously those strategy teachings that question IO and, by implication, challenge existing antitrust law..$^{93}$ The modern evolution of antitrust law has largely corresponded, albeit with a lag, to the evolution of economics generally and IO in particular. Strategy has strong roots in economics but it is not defined by economics. The field of strategy has much to offer the antitrust community, including its ability to serve as an example of how to navigate the gravitational pull of economics.

93 Many antitrust doctrines, like other legal doctrines, reflect how society understands the various elements that inform the doctrine and represent society's best judgment of how to balance these oftentimes partially understood elements. Hence, the introduction of more precise mechanisms or the replacement of some doctrines with less precise but more accurate doctrines requires attention to not only what is added but also to the effect of the change on the overall balance of elements. 
